\title{
Automatic Application Of Graphic Design To Banner Model
}

\author{
Achmad Jauhari ${ }^{1}$, Devie Rosa Anamisa ${ }^{2}$, Sigit Susanto Putro ${ }^{3}$, Faizah Mauliana Rizqi ${ }^{4}$ \\ Faculty of Engineering, \\ University of Trunojoyo Madura \\ Bangkalan, Indonesia \\ 1 jauhariaja@gmail.com, 22devros_gress@yahoo.com, ${ }^{2}$ sigit.putro@trunojoyo.ac.id
}

\begin{abstract}
Banners are one of the promotional tools. Banners have been printed with digital printing. Banners are usually used as media announcements or conveying aspirations about an activity. Banner is a simplification of billboards. Banners are usually designed in portrait or vertical form. Until now, banner creation always uses design applications like Photoshop or CorelDraw. However, this application still requires accuracy in its use. In addition, the application to design still requires other applications that support it to be a beautiful banner. In addition the user must first know the function of the tool from the application before starting to design. Therefore, this research makes an automatic application for designing banner models. In this application to design the background choices needed first, then each background has a layout for the banner design until the process is complete. Some solutions for automatic applications in designing a banner starting from the background design that is influenced by the position of the image that matches the size of the banner has not been done. Hopefully this research will contribute by automatically giving banner promotion media in designing it to produce attractive appearance as desired and having high persuasive value compared to other design applications separately so that users can minimize design time because there is no need to design the background. Various tests are carried out by calculating the comparison of the time duration of the banner design with the automatic application and using the Photoshop application. Therefore, the application in this research has proven the effectiveness of visual and wide space in conveying messages digitally printing and supported by the placement of appropriate images. Automatic application testing for banner models has reached a faster time than using a Photoshop application which is a 60 minute time difference and the testing process uses design data in educational activities. In addition to testing based on the duration of time, this application has also produced a banner model with a background image size of around $1,024 \mathrm{~Kb}$ has reached a damaged image only an average of $13 \%$ smaller.
\end{abstract}

Keywords- Application; Automatic; Design Grapich; Banner

\section{INTRODUCTION}

Technological developments have now brought significant changes, especially in the world for design. Design is one of the attractions of a person to an item so that the design is needed by a company to promote its goods. Promotion is any form of communication used to inform, persuade, or remind people of products produced by organizations, individuals, or households [1]. Submission of information or promotion can be done in many ways, either through online media or print media. Online media is very much in demand. However, with online media can add to the habit of someone getting to know the virtual world so that a sense of lack of environmental care because there are no more people buying newspapers to read the news or see advertisements, all have focused on the gadget [2]. Some studies have shown that not everyone in Indonesia can access the internet. Therefore print media is also very necessary for promotion to add business value and support the success of the program. Media promotion is divided into two parts, such as: media above the line, such as: television, radio, cinema and newspapers and media under the line, such as posters, banners, brochures and multimedia presentations [3]. Each type of media has different characteristics, with almost the same ratio. Currently there are many social media that can help share information using the internet. However, information through print media is still an effective way.

One of the printing tools is a banner. Banners are one of the information media used to inform an activity or this is only to convey aspirations. Banners have varying shapes and sizes [4]. The design of the banner is adjusted to the theme that has been made. While the influencing elements of graphic design, such as: typography, layout, and color. Typography is a graphic design that is used to explain, representing a form of verbal communication that is expressed visually [5]. The layout is the management of forms, fields and other design elements into the field so that they become artistic [6]. The layout also has the main purpose of displaying text and image elements so that they are communicative and make it easy to receive the information conveyed. While colors can be grouped into four categories, namely: primary, secondary, tertiary and neutral. Color is used to communicate feelings, attract attention, identify products, or organize information. Color is very influential in decision making when buying products [7].

Some solutions for product design in the form of banners have been made. However, the solution is not to provide an automatic application in one process can produce a beautiful banner design. Applications commonly used for banner designs such as Photoshop or CorelDraw. However, this application still requires accuracy in its use. Photoshop is an application used to modify images or photos by digital photographers and advertising companies. While Coreldraw is a vector graphics editor based on mathematical equations [8]. Photoshop or Coreldraw has the ability to read and write raster and vector format images such as .png, .gif, .jpeg, and others. But to be able to use this application, the user needs time to learn the 
tools that are in Photoshop or Coreldraw. So it takes a long time. Therefore, this research makes an automatic application for designing banner models. The purpose of this research is to be able to automatically provide banner promotion media to design it so as to produce an attractive appearance as desired and have high persuasive value compared to other design applications separately and can minimize design time because there is no need to design the background first.

\section{RESEARCH METHODS}

Banners are banners derived from the Latin "banderia" or "bandum". The banner itself according to Wikipedia is a flag or piece of cloth containing symbols, logos, slogans or other messages [9]. The development of banners is used as a medium for good promotion by large companies to the street vendors. Banners are installed in high-rise buildings, strategic locations reach villages. As a promotional media, banners are categorized as below the line media. Below the line media is an advertising activity that does not involve advertising in the mass media. Therefore, the banner is a medium whose nature makes it easy for the public to see one message or one product. Promotional media banners have several characteristics such as: large enough reach and cheap production costs (as strength). While the weaknesses, the information displayed is limited, the capacity is low, tax costs and licensing are high, security is not guaranteed, if the position is not strategic and the right segmentation that is not targeted is not achieved. But the discourse structures that will be studied about are Theme (Thematic), Source, Audience, Location where the banner is installed, the time it is installed and the Rhetoric. This is the most important piece of information from the text that has been conveyed to everyone. Image size in the background greatly affects the quality of the printed banners in a promotional media. A good picture is usually a large file size. Images are affected by image dimensions (length and width) and image depth (bits per pixel). The dimensions of the image are quite clear, what is the length and width of an image in pixel units. For example: $640 \times 480,800 \times 600,1024 \times 768$, etc. While the depth of the image is the space provided to hold color information in one pixel (Pixels are the smallest units of the image dimension). For example we have an image file with a size of $100 \times 100$ pixels, a depth of 24 bits. Then the original file size is: $100 \times 100 \times 24=240000$ bit $=240000 / 8$ Byte $=30000$ Byte $=29.30 \mathrm{~KB}$.

The input data in this study is the data background for 5 activities, such as: entertainment, sports, education, Is lamic activities, etc. Furthermore, data analys is has been collected to gradually create applications, including: system design using UML, designing interfaces, coding using the Visual C \# 2010 programming language, and implementing applications using Microsoft Windows 8.1 Pro 64 bit operating systems. In the design phase UML will be explained about the design of the application system model. The design of this application system model is used to define in detail the devices, processes or systems so that they can be realized in physical form [10]. The model produced during the design describes "how" the problem is solved in the form of software specifications that are ready to be implemented [11]. Interface design designs the interface for this application. While the coding stage, the program code is created and explained. The last stage is the stage of applying automatic graphic design applications for banner models.

The usecase diagram is an illustration of the interaction between the components of a system to be built [12]. Users can access the main menu which consists of 3 menu options, the menu selects the background, the image input menu and the text input menu for the banner title, can be seen on Fig 1. While the interface is needed an application that helps users to see the desired appearance, and provide comfort in seeing it. In this interface design must be considered the things needed by the user [13]. In this study the interface design can be seen in Fig 2 and an explanation of Fig 2 can be seen in Table 1 . Flowchart is a series of charts that illustrate the flow of the program, can be seen in Fig 3.

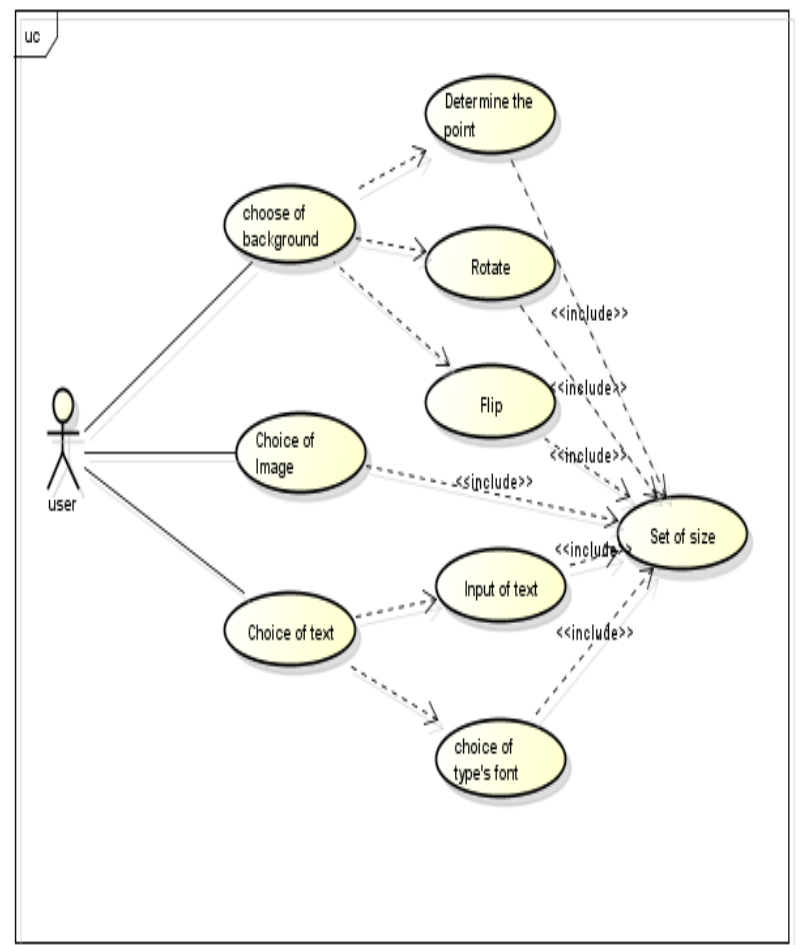

Fig. 1. Usecase Diagram of Automatic Automatic Application of Graphic Design to Banner Model

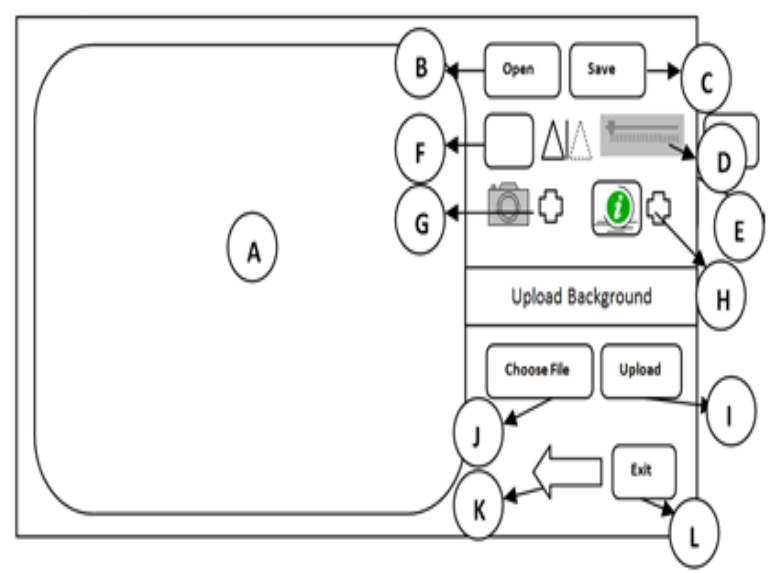

Fig. 2. Interface Design 


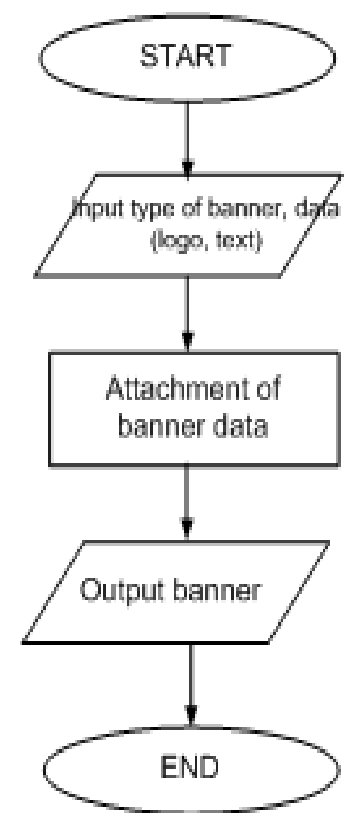

Fig. 3. Description of The Interface Design

TABLE I. DESCRIPTION OF THE INTERFACE DESIGN

\begin{tabular}{|c|c|}
\hline Name & Function \\
\hline A & Picturebox is a background place and enter the picture \\
\hline B & $\begin{array}{l}\text { The open button is the button used to open the } \\
\text { background file directory }\end{array}$ \\
\hline $\mathrm{C}$ & $\begin{array}{l}\text { To save the results of the banner that has been } \\
\text { created }\end{array}$ \\
\hline $\mathrm{D}$ & Change the background size that has been input \\
\hline $\mathrm{E}$ & The flip serves to mirror images \\
\hline $\mathrm{F}$ & To rotate the image 90 degrees \\
\hline G & To add images to the background \\
\hline $\mathrm{H}$ & To add text to the background \\
\hline I & To move background / upload background files \\
\hline $\mathrm{J}$ & $\begin{array}{l}\text { To open the background file directory that will be } \\
\text { uploaded }\end{array}$ \\
\hline K & To return to home \\
\hline $\mathrm{L}$ & To exit the application \\
\hline
\end{tabular}

\section{RESULTS AND DISCUSSION}

The results of the research are done by displaying a menu that can be accessed by the user, with several menu options. In this initial view only consists of background and buttons, there are two buttons, namely Start Design, and About. For Start Design itself is a button that points to the main menu of the program. When the button is clicked, the user will immediately see the core display or the main menu of the program. Display to add an image, can be seen in Fig 4. While the display for entering text can be seen in Fig 5 .

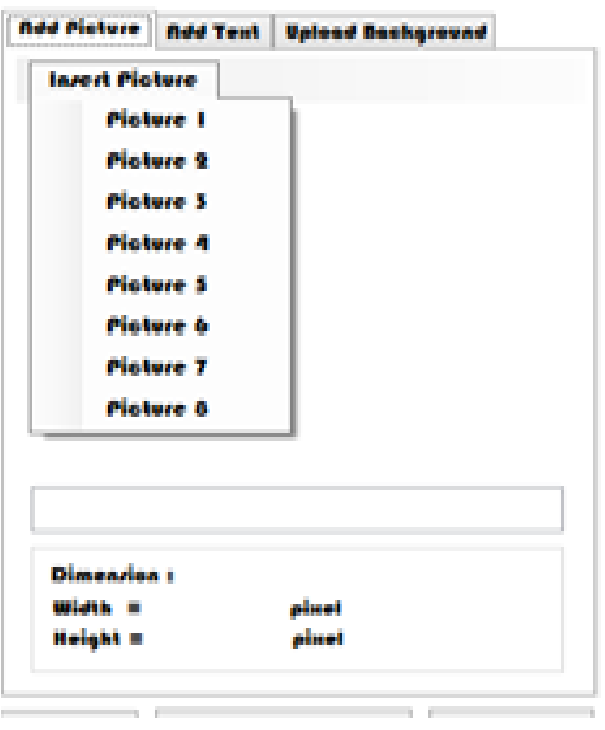

Fig. 4. Menu of Add The Picture

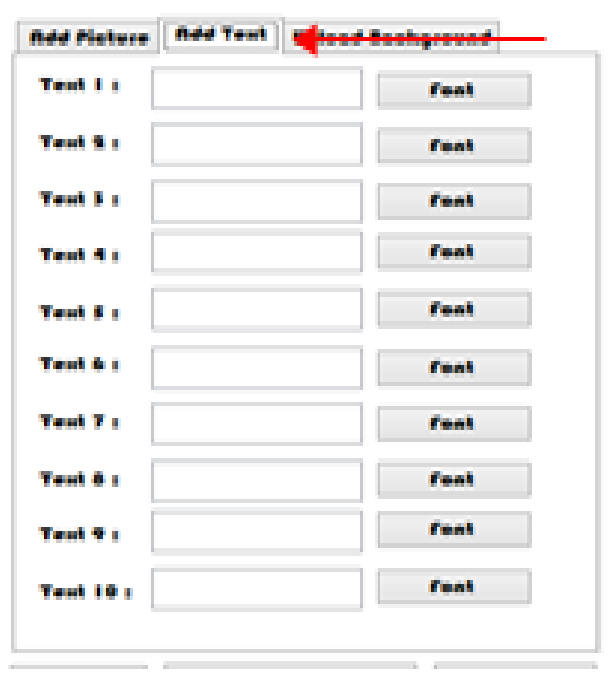

Fig. 5. Menu of add The Text

Several trials have been conducted in this study by calculating the comparison of the length of time to design banners with automated applications and banner designs using Photoshop applications, can be seen in Table 2. Trials through automated applications for banana design have reached a faster time than using design applications using photoshop. In 
addition the trial was carried out based on the size of the image in an activity. Activity categories in banners will certainly affect the effectiveness of delivering a message. For this reas on in conveying messages in the form of images on education and entertainment activities has reached a size of $1024 \mathrm{~Kb}$, for more details can be seen in Fig 6 .

TABLE II. RESUlt OF TIME CALCULATION

\begin{tabular}{|l|l|l|}
\hline \multicolumn{1}{|c|}{ PROCESS } & \multicolumn{2}{|c|}{ Duration Time (minutes) } \\
\cline { 2 - 3 } & \multicolumn{1}{|c|}{ Photoshop } & \multicolumn{1}{c|}{ This Software } \\
\hline DETERMINE SIZE & 10 & 10 \\
\hline ENTER TEXT & 15 & 15 \\
\hline MODIFY TEXT & 45 & 15 \\
\hline $\begin{array}{l}\text { MODIFY } \\
\text { BACKGROUND }\end{array}$ & 45 & 15 \\
\hline
\end{tabular}

\section{RESULT OF SIZE BROKEN IMAGE TO SEVERAL ACTIVITY}

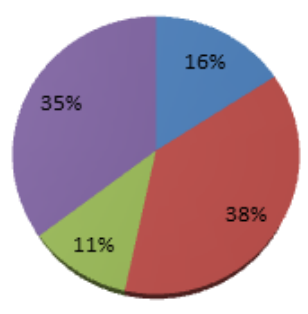

Entertaiment $1024 \mathrm{~KB}$

- Islamic's Event 2930 KB

Education $1024 \mathrm{~Kb}$

- Sport 1536 KB

Fig. 6. Result of Size Broken Image Background of Banner

\section{CONCLUSIONS AND FUTHER RESEARCH}

Banners are one of the promotional media as media announcements or convey as pirations about an activity. Banner is a simplification of billboards. Until now, banner creation always uses design applications like Photoshop or CorelDraw. However, applications in Photoshop or CorelDraw still require precision in their use. In addition, Photoshop or CorelDraw for design still requires other applications that support it to be a beautiful banner. users in the Photoshop or CorelDraw application must first know the function of the tool from the application before starting to design. Therefore, this research makes an automatic application for designing banner models. In this application to design the necessary background choices first, then each background has a layout for banner design until the process is complete. Some solutions for automatic applications in designing banners starting from the background design that is influenced by the position of the image in accordance with the size of the banner has not been done. Based on the results of research that has been done on visual graphic design applications for banner models by providing background choices and there are children who currently with banner designs reach a faster completion using Photoshop or Corel Draw applications, which have reached 60 times a minute, free on table 3 . although there are some things that are faster than design applications using photoshop. In addition to conveying the message in the form of an image on the activity will affect the image in the delivery of the message, shown in Figure 6, where the image size as a background with a size of $1024 \mathrm{~Kb}$ has reached the damaged image only an average of $13 \%$ smaller. Therefore this application is very helpful for users to make banners with simple tools. and easily understood by users who have never used well-known editing applications such as Adobe Photoshop and Corel Draw, and can allow design time. Therefore, the application in this research has proven the effectiveness of visual and wide space in conveying messages digitally printing and supported by the placement of appropriate images.

\section{ACKNOWLEDGMENT}

We would like to thank our fellow researchers in the University of Trunojoyo Madura-Indonesia, the entire team at the lab research that have helped the completion of this research, and Informatic Engineering Department and the Network which has provided an opportunity to use laboratory equipment.

\section{REFERENCES}

[1] Deri and B. Prabawa, , "Identity \& Promotional Media of Diradio.net. Jurnal Komunikasi Visual Wimba, Vol 6 (1), pp 57-70, 2014

[2] Nurkinan, "The Impact of Online Media on the Development of Conventional Media,” J. Politikom Indonesian, Vol 2 (2), pp 28-42, 2017

[3] E.K. Clow, and D. Baack, "Integrated Advertising, promotion, and Marketing Communication", Edisi 3, New Jersey: Pearson Education, Inc, 2007

[4] S,.L. Anggraini and K. Nathalia, "Visual communication design; Guide Basics for Beginners", 2014

[5] A. Kusrianto, "Introduction to Visual Communication Design", Yogyakarta: C.V Andi, 2007

[6] M. Suyanto, "Graphic Design for Advertising", Yogyakarta: Andi, 2004

[7] M. Lee, and C. Johnson, "Principles of Advertising in a Global Perspective", Jakarta: Kencana Prenada Media Group, 2007

[8] H. Setyawan, "Use of Coreldraw and Adobe Photoshop applications for Digital Image Watermarking Digital Archives", J. Archives of UGM Archives, pp. 26-40, 2017

[9] Eriyanto, "Introduct ory Analysis of Media Text Analysis", Yogyakarta: LKIS Yogyakarta, 2007

[10] R. S. Pressman, "Software Engineering: A Practicioner's Approach, 7th Edition, New York: McGraw-Hill Inc, 2010

[11] Wijaya, Mulyanto, and Mustakim, "Web and Wap-based New Student Admissions Information System", National Conference VI SDM Nuclear Technology, 18 November 2010 
[12] J. Rumbaugh, I. Jacobson, and G. Booch, "The Unified Modeling Language Reference Manual Second Edition", Canada: Pearson Education, 2005

[13] D.T. Bauer, S. Guerlain, and P.J. Brown, "The Design and Evaluation of Graphical Display for Laboratory Data", 2010 